\title{
Autonomic Nervous Activity in Multiparous Women during Early Postpartum Period: A Descriptive Study
}

\author{
Michiko Nakakita-Kenyon \\ Faculty of Nursing Kyoritsu Women's University, Tokyo, Japan \\ Email: mkenyon@kyoritsu-wu.ac.jp
}

How to cite this paper: Nakakita-Kenyon, M. (2017) Autonomic Nervous Activity in Multiparous Women during Early Postpartum Period: A Descriptive Study. Open Journal of Nursing, 7, 734-742.

https://doi.org/10.4236/ojn.2017.77055

Received: June 6, 2017

Accepted: July 9, 2017

Published: July 12, 2017

Copyright $\odot 2017$ by author and Scientific Research Publishing Inc. This work is licensed under the Creative Commons Attribution International License (CC BY 4.0).

http://creativecommons.org/licenses/by/4.0/ (c) (i) Open Access

\begin{abstract}
Background: The purpose of the present study is to analyze the autonomic nervous activity in multiparas while resting, nursing, and rooming-in/rooming-out during days 1 to 3 of early postpartum period. Methods: Subjects were asked to record the actions they performed while wearing a heart rate monitor. Changes in autonomic nervous activity from 9 am to $12 \mathrm{pm}$ and relaxation based on the relaxation (RE) scale were surveyed in multiparous women experiencing a normal postpartum period, on postpartum days 1 to 3. Results: Thirteen subjects were enrolled but heart rate data for all 3 days were available for only 5 of them. In these patients, the autonomic nervous activity (heat rate, high frequency $[\mathrm{HF}]$, or low frequency [LF]/HF) showed no significant differences between the days during any of the time periods. However, of the 3 days, day 2 demonstrated a lower HF and higher LF/HF. Subjective sense of relaxation was higher on postpartum day 3 compared to days 1 and 2, but there was no significant difference observed in the 3-day total score. Though no significant differences in $\mathrm{HF}$ and $\mathrm{LF} / \mathrm{HF}$ at rest and during nursing were observed for any of the 3 days, there was a tendency for HF to be lower and $\mathrm{LF} / \mathrm{HF}$ to be higher during nursing than at rest. Conclusions. Autonomic nervous activity demonstrated no significant major changes between the 3 days of postpartum (day 1 to 3). However, the lower HF and higher LF/HF during nursing and rooming-in suggest that even multiparas, who are supposedly accustomed to nursing and child-rearing, can be tense. Results suggest that multiparas require monitoring, personal care, and attention so that they can be relaxed and less tense while nursing and caring for their children.
\end{abstract}

\section{Keywords}

Autonomic Nervous Activity, Early Postpartum, Multiparous Women, Rooming-In, Nursing 


\section{Introduction}

Immediately after delivery, a woman undergoes significant physical and mental changes, with changes in sex hormones and autonomic nervous activity, leaving her prone to, both, physical and mental crises. Nakakita [1] noted that autonomic nervous activity in women who have recently delivered puts them potentially at risk of entering an unstable state, especially on postpartum day 1 . Hasegawa [2] has also reported that many women who have recently undergone childbirth have non-specific complaints, and these complaints that arise in this period are due to changes in their autonomic nervous activity.

Previous research in women in the early postpartum period has shown that their sense of relaxation and age are related to changes in autonomic nervous activity [3], and that women who have recently delivered and have high levels of stress have higher sympathetic nervous activity on postpartum day 1 [4]. Primiparas are at high risk of post-partum blues, and due to the first experience with childbirth, they require nursing care as well as guidance while in the hospital. In contrast, multiparas, having experienced childbirth, receive lesser nursing care or guidance while in the hospital after giving birth. Nonetheless, clinically, it is not uncommon even for multiparas to complain of anxiety or tension, and require care that will produce a sense of relaxation. Mental and physiological imbalances in multiparas have been hypothesized to be possibly related to autonomic nervous activity, influencing factors different from those observed in primiparas, and factors other than pregnancy and delivery [3]. However, existing data is insufficient to investigate such theories. Therefore, there is a need to study the features of autonomic nervous activity in multiparas, and develop nursing care based on the results.

The purpose of the present study is to study the autonomic nervous activity of multiparas while resting, nursing, and rooming-in/rooming-out during the early postpartum period.

\section{Material and Methods}

\subsection{Study Design}

The present study used a survey with experimental techniques.

\subsection{Study Participants and Data Collection Period}

The study was conducted at an obstetrics and gynecology facility in Japan's Kanagawa Prefecture. The participating facility implements rooming-in only during the day (11 am to $9 \mathrm{pm}$ ); at night, neonates are cared for in the nursery, allowing their mothers to have ample sleep. On the morning of postpartum day 2 , they receive guidance on nursing and infant bathing.

The subjects were women going through postpartum days 1 - 3. Inclusion criteria included multiparity, birth weight of the neonate of at least $2500 \mathrm{~g}$, a favorable state of health after delivery in both mother and child, and rooming-in care for the neonate during the day. Exclusion criteria included a prior history 
that would affect the autonomic nervous activity, cesarean section, loss of $500 \mathrm{~g}$ or more of blood during delivery, diseases such as jaundice that requires phototherapy or birth defects in the child. The study period was from September to November 2015.

The purpose of the study was explained and an informed consent was obtained from the participating patients. The study design was approved by the Toho University Faculty of Nursing research ethics review committee (approval no.: 26016).

\subsection{Measurement Apparatuses}

Subjects were asked to fill out a questionnaire with basic information such as age, number of deliveries, age of previous child/children ( $\geq 3$ years or $<3$ years), and family structure, as well as information on the delivery (duration of labor, child's birth weight, loss of blood during delivery, and whether an episiotomy was performed). They were also asked to respond to questions regarding their current state (extent of physical symptoms and state of relaxation). Subjects were asked to keep a simple log of actions performed while wearing a heart rate monitor.

A miniature heart rate recording device, ActiHR4 (CamNtech Ltd and CamNtechInc, England), was used to record the heart rate, which was then analyzed through frequency analysis on a personal computer.

For autonomic nervous activity, I measured high frequency (HF) and low frequency (LF)/HF. HF is representative of parasympathetic nervous activity, and the LF/HF ratio is an indicator of sympathetic nervous activity [5] [6] [7]. HF was analyzed after logarithmic conversion $(\log 10)$, because of considerable individual differences and variations in the distribution of frequency domains.

Emotional state and relaxation were scored on a RE scale using the questionnaire. The RE scale is a self-administered questionnaire developed by Netate and Uesato [8]. I used the modified version from Takahashi et al. [9], which uses a 10-point rating scale. Respondents use 10 points to rate the following four items: "I was feeling high-strung/I was feeling relaxed", "I had strength in my body/My body had lost strength", "I was anxious/I had peace of mind", and "I felt confined/I felt open and free". The higher the score, the stronger is the sense of relaxation.

\subsection{Data Collection Method}

The subjects wore the heart rate monitor for 3 hours-from 9 am to $12 \mathrm{pm}-$ from postpartum day 1 to day 3. The heart rate measurements were analyzed through frequency analysis to calculate autonomic nervous activity (sympathetic nervous activity and parasympathetic nervous activity).

\subsection{Statistical Analysis}

The statistical analysis was performed with SPSS Statistics 22 (IBM, USA). The subjective attributes were analyzed with descriptive statistics. The three-day 
changes in heart rate, HF, and LF/HF were analyzed by repeated-measures one-way analysis of variance and paired t-test. The level of significance was set at $5 \%$, with two-sided tests in all instances.

\section{Results}

\subsection{Participant Attributes}

Of the 13 subjects, data of all 3 days was obtained from 5 and their attributes are shown in Table 1 . The mean age was $32.6 \pm 3.84$ years. Four women had previously experienced one childbirth while one woman experienced two childbirths. The mean neonatal birth weight was $3039 \pm 284.4 \mathrm{~g}$, duration of labor was $346.8 \pm 128.8 \mathrm{~min}$, and blood loss was $232.6 \pm 78.1 \mathrm{~g}$. All 5 women were from nuclear families. Three women had children under 3 years of age. Childcare during hospitalization was provided by the husbands alone in 3 women and by the woman's parents in 2 women.

\subsection{Three-Day Changes in Autonomic Nervous Activity and RE Scale}

None of the items-heart rate, HF, or LF/HF, showed any significant differences for the 3 days after childbirth (Table 2). However, of the 3 days, day 2 had the lowest $\mathrm{HF}$ values, and highest LF/HF. On the RE scale, the mean RE score was $25.6 \pm 5.4$ points for day $1,25.4 \pm 6.3$ points for day 2 , and $29.2 \pm 4.1$ for day 3 . Compared with postpartum day 1 and day 2, a rise in scores was observed on day 3, but there was no significant difference observed in the total RE scores between the 3 days after birth $(F=2.378, p=0.195)$.

Table 1. Subject characteristics.

\begin{tabular}{cc}
\hline Number of subjects & 5 \\
Mean age (years) & $32.6 \pm 3.84$ \\
Duration of labor (min) & $346.8 \pm 128.8$ \\
Child's birth weight (g) & $3039 \pm 284.4$ \\
Average blood loss (g) & $232.6 \pm 78.1$ \\
Prior childbirth experience: & \\
One prior pregnancy & $4(80.0 \%)$ \\
Two prior pregnancies & $1(20.0 \%)$ \\
\hline
\end{tabular}

Table 2. Three-day changes in autonomic nervous activity.

\begin{tabular}{cccccc}
\hline & \multicolumn{3}{c}{ Days after birth } & \multirow{2}{*}{-value } & p-value \\
\cline { 2 - 4 } & Day 1 & Day 2 & Day 3 & & \\
\hline $\begin{array}{c}\text { Mean Heart rate (beats/min) } \\
\begin{array}{c}\text { Parasympathetic nervous } \\
\text { activity indicator HF (msec }\end{array}\end{array}$ & $77.3 \pm 8.6$ & $81.0 \pm 9.1$ & $77.9 \pm 7.2$ & 0.801 & 0.482 \\
$\begin{array}{c}\text { Sympathetic nervous activity } \\
\text { indicator LF/HF (msec }\end{array}$ & $2.80 \pm 0.64$ & $2.29 \pm 0.25$ & $2.60 \pm 0.71$ & 0.730 & 0.511 \\
\hline
\end{tabular}




\subsection{Actions Affecting Autonomic Nervous Activity Units}

Of the 3 hours when the heart rate monitor was worn, rest was defined as the time when the activity log showed "Slumber", "Time spent in bed", and "Leisurely resting", and the mean autonomic nervous activity during this period was calculated. The total resting time spent by each subject was 1 to 1.5 hours/3 hours. HF at rest was $2.54 \pm 0.43 \mathrm{msec}^{2}$ on day $1,2.61 \pm 0.42 \mathrm{msec}^{2}$ on day 2 , and $2.70 \pm 0.34 \mathrm{msec}^{2}$ on day $3 . \mathrm{LF} / \mathrm{HF}$ was $2.24 \pm 1.12 \mathrm{msec}^{2}$ for day $1,2.18 \pm 1.93$ $\mathrm{msec}^{2}$ for day 2 , and $2.20 \pm 1.60 \mathrm{msec}^{2}$ for day 3 .

Time that was logged as nursing was counted as nursing, and the mean autonomic nervous activity during this period were calculated. HF during nursing was $2.26 \pm 0.36 \mathrm{msec}^{2}$ on day $1,2.09 \pm 0.38 \mathrm{msec}^{2}$ on day 2, and $2.05 \pm 0.54$ $\mathrm{msec}^{2}$ on day 3 . LF/HF was $2.72 \pm 1.06 \mathrm{msec}^{2}$ for day $1,3.77 \pm 2.39 \mathrm{msec}^{2}$ for day 2 , and $3.02 \pm 1.24 \mathrm{msec}^{2}$ for day 3 (Table 3 ).

$\mathrm{HF}$ and $\mathrm{LF} / \mathrm{HF}$ at rest and during nursing did not show a significant difference on any of the days. However, compared with nursing, HF and LF/HF at rest were lower and higher, respectively. Furthermore, compared with the 3-hour mean, $\mathrm{HF}$ and $\mathrm{LF} / \mathrm{HF}$ at rest were also lower and higher, respectively.

We compared $\mathrm{HF}$ and $\mathrm{LF} / \mathrm{HF}$ during rooming-in and rooming-out, which began at $11 \mathrm{am}$. HF during rooming-out was $2.54 \pm 0.28 \mathrm{msec}^{2}$ on day $1,2.35 \pm$ $0.27 \mathrm{msec}^{2}$ on day 2 , and $2.51 \pm 0.35 \mathrm{msec}^{2}$ on day 3. During rooming-in, it was $2.27 \pm 0.33 \mathrm{msec}^{2}$ on day $1,2.18 \pm 0.35 \mathrm{msec}^{2}$ on day 2 , and $2.10 \pm 0.50 \mathrm{msec}^{2}$ on day 3. LF/HF during rooming-out was $2.28 \pm 0.92 \mathrm{msec}^{2}$ on day $1,2.84 \pm 1.87$ $\mathrm{msec}^{2}$ on day 2 , and $2.58 \pm 1.26 \mathrm{msec}^{2}$ on day 3; during rooming-in, it was $3.12 \pm$ $0.55 \mathrm{msec}^{2}$ on day $1,3.69 \pm 1.61 \mathrm{msec}^{2}$ on day 2 , and $3.91 \pm 1.57 \mathrm{msec}^{2}$ on day 3 . $\mathrm{HF}$ and LF/HF during rooming-in and rooming-out did not show a significant difference for any of postpartum days 1 to 3, but compared with rooming-out, rooming-in HF was lower and rooming-in LF/HF was higher (Table 4).

Table 3. Comparison of autonomic nervous activity at rest and during nursing over 3 days.

\begin{tabular}{|c|c|c|c|c|}
\hline & \multicolumn{2}{|c|}{$\mathrm{HF}\left(\mathrm{msec}^{2}\right)$} & \multicolumn{2}{|c|}{$\mathrm{LF} / \mathrm{HF}\left(\mathrm{msec}^{2}\right)$} \\
\hline & At Rest & During Nursing & At Rest & During Nursing \\
\hline \multicolumn{5}{|c|}{ Postpartum Day 1} \\
\hline Mean \pm SD & $2.54 \pm 0.43$ & $2.26 \pm 0.36$ & $2.24 \pm 1.12$ & $2.72 \pm 1.06$ \\
\hline$t$-value & \multicolumn{2}{|c|}{-1.015} & \multicolumn{2}{|r|}{0.549} \\
\hline$p$-value & \multicolumn{2}{|r|}{0.368} & \multicolumn{2}{|r|}{0.612} \\
\hline \multicolumn{5}{|c|}{ Postpartum Day 2} \\
\hline Mean \pm SD & $2.61 \pm 0.42$ & $2.09 \pm 0.38$ & $2.18 \pm 1.93$ & $3.77 \pm 2.39$ \\
\hline$t$-value & \multicolumn{2}{|c|}{-2.107} & \multicolumn{2}{|r|}{2.007} \\
\hline$p$-value & \multicolumn{2}{|r|}{0.103} & \multicolumn{2}{|r|}{0.115} \\
\hline \multicolumn{5}{|c|}{ Postpartum Day 3} \\
\hline Mean \pm SD & $2.70 \pm 0.34$ & $2.05 \pm 0.54$ & $2.20 \pm 1.60$ & $3.02 \pm 1.24$ \\
\hline$t$-value & \multicolumn{2}{|c|}{-2.625} & \multicolumn{2}{|r|}{1.282} \\
\hline$p$-value & \multicolumn{2}{|r|}{0.059} & \multicolumn{2}{|r|}{0.269} \\
\hline
\end{tabular}


Table 4. Comparison of autonomic nervous activity during rooming-out and rooming-in over 3 days.

\begin{tabular}{|c|c|c|c|c|}
\hline & \multicolumn{2}{|c|}{$\begin{array}{l}\text { Parasympathetic nervous activity } \\
\text { indicator } \mathrm{HF}\left(\mathrm{msec}^{2}\right)\end{array}$} & \multicolumn{2}{|c|}{$\begin{array}{l}\text { Sympathetic nervous activity } \\
\text { indicator LF/HF ( } \mathrm{msec}^{2} \text { ) }\end{array}$} \\
\hline & Rooming-out & Rooming-in & Rooming-out & Rooming-in \\
\hline \multicolumn{5}{|c|}{ Postpartum Day 1} \\
\hline Mean \pm SD & $2.54 \pm 0.28$ & $2.27 \pm 0.32$ & $2.28 \pm 0.92$ & $3.12 \pm 0.55$ \\
\hline$t$-value & \multicolumn{2}{|c|}{1.241} & \multicolumn{2}{|c|}{-1.754} \\
\hline$p$-value & \multicolumn{2}{|c|}{0.283} & \multicolumn{2}{|c|}{0.154} \\
\hline \multicolumn{5}{|c|}{ Postpartum Day 2} \\
\hline Mean \pm SD & $2.35 \pm 0.27$ & $2.18 \pm 0.35$ & $2.84 \pm 1.87$ & $3.69 \pm 1.61$ \\
\hline$t$-value & \multicolumn{2}{|c|}{1.166} & \multicolumn{2}{|c|}{-1.373} \\
\hline$p$-value & \multicolumn{2}{|c|}{0.308} & \multicolumn{2}{|c|}{0.242} \\
\hline \multicolumn{5}{|c|}{ Postpartum Day 3} \\
\hline Mean \pm SD & $2.51 \pm 0.35$ & $2.10 \pm 0.50$ & $2.58 \pm 1.26$ & $3.91 \pm 1.57$ \\
\hline$t$-value & \multicolumn{2}{|c|}{1.683} & \multicolumn{2}{|c|}{-2.376} \\
\hline$p$-value & \multicolumn{2}{|c|}{0.168} & \multicolumn{2}{|c|}{0.076} \\
\hline
\end{tabular}

\section{Discussion}

After the text edit has been completed, the paper is ready for the template. Duplicate the template file by using the Save As command, and use the naming convention prescribed by your journal for the name of your paper. In this newly created file, highlight all of the contents and import your prepared text file. You are now ready to style your paper.

\subsection{Autonomic Nervous Activity and Sense of Relaxation during the Early Postpartum Period}

The results of the present study do not show significant fluctuations in autonomic nervous activity or subjective sense of relaxation over the immediate post-partum 3 days. Mizuno et al. [4] has suggested that women who present with psychological stress during the perinatal period have elevated sympathetic nervous activity along with diminished parasympathetic nervous activity in the early postpartum period when compared with women who do not develop psychological stress. However, because none of the results of the present study demonstrated a significant difference and the small sample size, the present study has failed to show a modulation of autonomic nervous activity in the early postpartum period in multiparas.

Hayashi [6] stated that HF is higher in the morning than afternoon and circadian variations in cardiac parasympathetic nervous activity are endogenous. Nevertheless, it may be possible that the lower parasympathetic nervous activity observed during nursing and rooming-in when compared with rest and rooming-out are due to tension/excitation brought on by the child's presence. Further investigation to study is this is truly a physiological response is needed. 
In previously reported research on autonomic nervous activity in women who have recently given birth [1] [2] [4] [10], the measurement time was 5 to $15 \mathrm{mi}$ nutes, and measurement at rest was based on an experimentally prepared environment. Therefore, the measurement of heart rate and its variability over 3 hours, as done in the present study, is a better representation of the reality of autonomic nervous activity in these women. Despite the longer period of observation, it is difficult to determine if these findings were disorders of autonomic nervous activity or were attenuated results due to measuring at certain time of the day only. Thus, further studies investigating the autonomic nervous activity over 24 hours are required for better quality of data.

Izumi et al. [11] suggested the possibility that assessing autonomic nervous activity by heart rate variability could help detect women who have recently given birth and are at risk of anxiety or depression. The results in the present study demonstrate that careful analysis of changes in autonomic nervous activity during the immediate post-partum period for each individual mother along with subjective indicators, may lead to quicker identification of disruptions in the autonomic nervous activity and early detection of maternity blues, and postpartum depression.

\subsection{In-Hospital Care for Multiparas}

Postpartum women reportedly experience relaxation, decreased anxiety, and happier mood when oxytocin is secreted from the posterior pituitary in response to nursing, and reportedly experience its long-term stress-reducing effects [12]. However, in the present study, autonomic nervous activity did not differ significantly between rest and nursing, and though not a major deviation from the norm, the parasympathetic nervous activity was lower and the sympathetic nervous activity was higher during nursing than at rest. Morimoto et al. [13] also reported that though prior experience with childbirth alleviated the basic fears associated with it, it did not provide total relief from childbirth and raising children. Therefore though multiparas may not be in acute need of follow-up care such as techniques of raising children, it is necessary to understand the neonate's individuality and characteristics and the differences from the older child (ren), and acclimatization to the child requires some time and support. In a study by Ono and Manabe [14] in primiparas, mothers with a strong stress response in the week after birth had continued to maintain their stress response 4 weeks later, and their sense of efficacy as a parent was also reduced; they reportedly had a strong sense of constraint due to childcare, and around $90 \%$ of mothers recognized nighttime or post-nursing crying by the child as a source of stress. Thus, during the early postpartum period, some mothers potentially experience stress while nursing, even though they may have prior experience with nursing. Therefore, in the early postpartum period in the hospital, not only primiparas but also multiparas require care that reduces stress or keeps it under control, so that their stress remains within the physiological range. Doing so may require mental and physical care, personal care and attention, and monitoring that in- 
duces relaxation during child-care.

The results of the present study are from a small sample size and a single facility; further clarification of autonomic nervous activity in multiparas will require further studies with a greater number of subjects. If child-care, including nursing, and time spent in rooming-in together with the child are regarded stressful by the mothers in the early postpartum period, then mothers going through complete rooming-in and nursing at night, as well, can be expected to be more prone to disruptions in their autonomic nervous activity. Enhanced care for mothers caring for their children may require detailed assessments of their daily autonomic nervous activity in the hospital and data that is better reflective of reality.

\section{Conclusions}

The present study clarifies the following matters.

1) Changes in autonomic nervous activity and a sense of relaxation on postpartum days 1 to 3 are not significantly different.

2) Although significant differences were not observed in autonomic nervous activity between rest and nursing, or rooming-out and rooming-in, HF and LF/ HF values were lower and higher, respectively, during nursing and rest. HR and $\mathrm{LF} / \mathrm{HF}$ values were also lower and higher, respectively, during rooming-in than rooming-out.

In the early postpartum period immediately after childbirth, even multiparas with prior experience with nursing and child-care were found to be in a state of stress. Results suggest that even multiparas require ample care, monitoring, and personal attention until they understand the child's characteristics and a bond between the mother and child can be established.

\section{Acknowledgements}

The author is grateful to the mothers who so kindly participated in this study as well as the Director and nursing staff of the cooperating facility. This study was funded by the 2013-2015 Scientific Research Assistance Fund from The Ministry of Education, Culture, Sports, Science and Technology (Grants-in-Aid for Young Scientists B, issue number 25862207).

\section{Conflict of Interest}

There is no conflict of interest that could be perceived as prejudicing the impartibility of the research reported.

\section{References}

[1] Nakakita, M. (2011) Autonomic Nervous System Activity by RR-Interval Variability and the Feeling of Relaxation in Postpartum Mothers-Variation per Day and Related Factors. Journal of Japan Academy of Midwifery, 25, 191-202. (in Japanese) https://doi.org/10.3418/jjam.25.191

[2] Hasegawa, N. (1974) Psychosomatic Medicine and Pregnancy/Childbirth. Perinatal 
Medicine, 4, 1000-1006. (in Japanese)

[3] Nakakita, M. (2012) Evaluation of the Autonomic Nervous System Activity, Somatic Symptoms, and Subjective Relaxation for Assessing the Mental and Physical Characteristics in Primiparae and Multiparae during the Early Postpartum Period. Japanese Journal of Maternal Health, 53, 98-106. (in Japanese)

[4] Mizuno, T., Goto, S. and Tanabe, K. (2015) Relationship between Perinatal Psychological Stress and Autonomic Nervous Activity. Japanese Journal of Maternal Health, 56, 311-319. (in Japanese)

[5] Hayano, J. (1996) Analysis of Functions of the Autonomic Nerve System by Means of Heart Rate Variability. In: Inoue, H., Ed, Cardiovascular Diseases and Functions of the Autonomic Nerve System, Igaku-Shoin, Tokyo, 58-88. (in Japanese)

[6] Hayashi, H. (1999) Introduction. In: Hayashi, H., Ed, Clinical Applications of Heart Rate Variability: Physiological Significance, Evaluation of Pathological Condition, and Prognostic Prediction, Igaku-Shoin, Tokyo, 1-36. (in Japanese) https://doi.org/10.1159/000052862

[7] Otsuka, K. (1998) Heart Rate Variability. In: Otsuka K, Ed, Chronome Medicine and Janus Medicine, Medical Review, Tokyo, 47-115. (in Japanese)

[8] Netate, K. and Uesato, I. (1984) Cognition of Physiological Response and Actual Effects of Physiological Response on Emotion. Behavioral Therapy Research, 9, 33-39. (in Japanese)

[9] Takahashi, M., Tagami, F., Shigemitsu, T. and Kubo, B. (1999) Comparison of Relaxation Effects of Image Methods and Autonomous Training Methods on Pregnant Women. Japanese Journal of Maternal Health, 40, 522-526. (in Japanese)

[10] Kanai, T., Izuka, M., Egawa, M., Miyasaka, T. and Kubota, T. (2016) Study on the Relationship between Postpartum Mental State and Autonomic Nervous Activity. Tokyo Journal of Maternal Health, 32, 28-34. (in Japanese)

[11] Izumi, M., Manabe, E., Uematsu, S., Watanabe, A., Iwasa, K. and Moritani, T. (2015) Trends in and Relationship between Autonomic Nervous Activity and Anxiety/Depression in the Year after Childbirth. Journal of Psychosomatic Obstetrics \& Gynecology, 20, 92-99. (in Japanese)

[12] UvnäsMoberg, K. (2008) Oxytocin. Trans. by Seo, T. and Tanigaki, A., Shobun-sha, Tokyo, 112-150. (in Japanese)

[13] Morimoto, M., Minasato, M., Yamauchi, M. and Nagamatsu, M. (2015) Relationship between Parenting Support Recognized by the Mother as Being Received During Hospitalization and Child-Rearing Anxiety up to 1 Month after Childbirth. Japanese Journal of Maternal Health, 56, 154-161. (in Japanese)

[14] Ono, M. and Manabe, E. (2013) Study on Characteristics of Parenting Stress in the 4 Weeks after Birth as Seen from the Stress Response 1 Week after Birth in Primiparas. Japanese Journal of Maternal Health, 54, 182-190. (in Japanese) 
Submit or recommend next manuscript to SCIRP and we will provide best service for you:

Accepting pre-submission inquiries through Email, Facebook, LinkedIn, Twitter, etc. A wide selection of journals (inclusive of 9 subjects, more than 200 journals)

Providing 24-hour high-quality service

User-friendly online submission system

Fair and swift peer-review system

Efficient typesetting and proofreading procedure

Display of the result of downloads and visits, as well as the number of cited articles Maximum dissemination of your research work

Submit your manuscript at: http://papersubmission.scirp.org/

Or contact ojn@scirp.org 